Overpressure Role in Isothermal Kinetics of $\mathrm{H}_{2}$ Desorption-Absorption: the

\title{
$2 \mathrm{LiBH}_{4}-\mathrm{Mg}_{2} \mathrm{FeH}_{6}$ System
}

Michele Catti, ${ }^{*}$ Mohammad R. Ghaani, and Ilya Pinus

Dipartimento di Scienza dei Materiali, Università di Milano Bicocca, via R. Cozzi 53, I-20125

Milano, Italy 


\begin{abstract}
The rates of the irreversibile $\mathrm{LiBH}_{4}+\mathrm{Mg}_{2} \mathrm{FeH}_{6} \rightarrow \mathrm{LiH}+2 \mathrm{MgH}_{2}+\mathrm{FeB}+5 / 2 \mathrm{H}_{2}$ and reversible (with significant sorption/desorption hysteresis) $\mathrm{LiBH}_{4}+1 / 2 \mathrm{Mg} \leftrightarrow \mathrm{LiH}+1 / 2 \mathrm{MgB}_{2}+3 / 2 \mathrm{H}_{2}$ reactions were measured by isothermal-isobaric experiments in a Sievert-type apparatus. Measurements were done at several temperature $T$ and overpressure $\Delta p / p$ values, deriving the rate constants $k(T, \Delta p / p)$ by Avrami's fitting of reaction advancement vs. time. The results could be rationalized on the basis of the $k=A \exp \left(-E_{a} / R T\right)=A_{0} \exp \left[-E_{a}^{0} / R T+a(\Delta p / p)\right]$ kinetic formula, which couples the standard Arrhenius approach for thermal effects with an exponential dependence of the rate constant on overpressure. The empirical $a$ coefficient varies with temperature in a way that requires the activation energy and entropy to depend linearly on $\Delta p / p$. For the first of the above reactions, $E_{a}=-151(\Delta p / p)+118 \mathrm{~kJ} \mathrm{~mol}^{-1}$ and $\ln \left(A / \mathrm{min}^{-1}\right)=-34(\Delta p / p)+16$; similar values are obtained for the second one. Relations of this kinetic model with the thermodynamic driving force $\Delta G$ and with equations of electrochemical kinetics, where overpressure is replaced by overvoltage, are discussed.
\end{abstract}

Keywords: hydrogen storage, solid-gas reactions, thermodynamic driving force, dehydrogenation, Arrhenius law 


\section{INTRODUCTION}

Combined dehydrogenation of assemblages of hydrides was suggested some years ago ${ }^{1}$ as a way of reducing the temperature of $\mathrm{H}_{2}$ yield, with respect to those of separate compounds. This would solve one of the most serious operational drawbacks of materials for hydrogen storage, i.e. the significant amount of energy to be consumed at the stage of $\mathrm{H}_{2}$ retrieval. ${ }^{2}$ The method was claimed to work when some of the products of the dehydrogenation reaction have large (negative) formation enthalpies, so that the (positive) reaction enthalpy decreases substantially. Several studies have shown that this is indeed the case for the $\mathrm{LiBH}_{4}-\mathrm{MgH}_{2}$ assemblage, because of the great stability of the $\mathrm{MgB}_{2}$ product of the reaction; ${ }^{3-6}$ further, first-principles calculations indicate that quite a number of other systems should share the same property. ${ }^{7}$ Along this line of research, we recently investigated the dehydrogenation reactions of the $2 \mathrm{LiBH}_{4}-\mathrm{Mg}_{2} \mathrm{FeH}_{6}$ assemblage from the thermodynamic point of view. ${ }^{8}$ This system is quite interesting, as it couples the very high gravimetric $\mathrm{H}_{2}$ density of lithium borohydride $(13.9 \%)^{9}$ to the very high volumetric hydrogen density of $\mathrm{Mg}_{2} \mathrm{FeH}_{6}\left(150 \mathrm{~kg} \mathrm{~m}^{-3}\right) .{ }^{10}$ Other studies on similar assemblages of these compounds have been recently reported. ${ }^{11,12}$

The main finding of our previous work ${ }^{8}$ is that dehydrogenation occurs in three subsequent steps, either on decreasing pressure isothermally, or increasing temperature isobarically:

$$
\begin{aligned}
& \text { (A) } 2 \mathrm{LiBH}_{4}+2 \mathrm{Mg}_{2} \mathrm{FeH}_{6} \rightarrow 2 \mathrm{LiH}+4 \mathrm{MgH}_{2}+2 \mathrm{FeB}+5 \mathrm{H}_{2} \text {, } \\
& \text { (B) } \mathrm{MgH}_{2} \rightarrow \mathrm{Mg}+\mathrm{H}_{2}, \\
& \text { (C) } 2 \mathrm{LiBH}_{4}+\mathrm{Mg} \rightarrow 2 \mathrm{LiH}+\mathrm{MgB}_{2}+3 \mathrm{H}_{2} .
\end{aligned}
$$

Step A is irreversible, at least for $p$ not exceeding 100 bar, whereas both B and C reactions are reversible. The van't Hoff line of reaction A is located at higher pressure and lower temperature with respect to those of both pure hydrides, proving that they are indeed destabilized by the joint 
decomposition reaction. However, this occurs by an increase of the reaction entropy rather than by decrease of reaction enthalpy, as found for the $\mathrm{LiBH}_{4}-\mathrm{MgH}_{2}$ system.

The first, yet minor, aim of the present investigation is to complete the thermodynamic study of this system by determining the van't Hoff plots of the B and C hydrogenation reactions. The major object is, on the other hand, to characterize the kinetic aspects of all processes of $\mathrm{H}_{2}$ exchange occurring with the $2 \mathrm{LiBH}_{4}-\mathrm{Mg}_{2} \mathrm{FeH}_{6}$ assemblage. For this purpose, the isothermal method ${ }^{13,14}$ has been chosen rather than the more usual temperature-ramp method with constant heating rate. ${ }^{15,16}$ In facts the selected approach, though requiring much longer measurements, gives fully time-resolved results which allow a rigorous and straightforward kinetic interpretation; the dynamic method, instead, is known to suffer some ambiguities in the separation of temperature and time dependences of the reaction progress (cf. the case of Kissinger's method ${ }^{17}$ ).

A peculiar objective of this work is also to investigate the role and kinetic importance of an additional physical parameter, the overpressure: this is defined as $\Delta p / p=\left(p-p_{e}\right) / p_{e}$, where $p_{e}(T)$ is the equilibrium $\mathrm{H}_{2}$ pressure calculated according to the van't Hoff equation. Overpressure is usually negative (underpressure) for dehydrogenation and positive for hydrogenation reactions. Further, it has a fundamental kinetic significance, as it is the source of the thermodynamic driving force $\Delta G$ for chemical reactions involving production or consumption of a gaseous phase. ${ }^{18,19}$ We thus here want to explore the empirical dependence of reaction rate constants on both $T$ and $\Delta p / p$, attempting to introduce the kinetic contribution of the driving force into the usual Arrhenius formalism.

\section{EXPERIMENTAL}

$\mathrm{Mg}_{2} \mathrm{FeH}_{6}$ was synthesized by reactive ball milling of $\mathrm{MgH}_{2}$ and $\mathrm{Fe}$ in stoichiometric ratio, and subsequent hydrogenation in a Sievert-type equipment. ${ }^{20,21}$ A Retsch planetary mill with stainless steel vial and balls was used, with the same conditions as in previous work (Ar atmosphere, $30 \mathrm{~h}$ at 
400 rounds $\min ^{-1}$, ball-to-powder weight ratio $=30$ ). Then the ball milled sample was loaded in an automatic Sievert-type apparatus (Advanced Materials Corporation), brought to $\mathrm{p}\left(\mathrm{H}_{2}\right)=100$ bar and then heated at $400{ }^{\circ} \mathrm{C}$ for 9 days. The final sample obtained proved to contain pure $\mathrm{Mg}_{2} \mathrm{FeH}_{6}$ and a small quantity of unreacted $\mathrm{Fe}$, with no traces of $\mathrm{MgH}_{2}$, according to X-ray powder diffractometry results (Bruker D8 Advance equipment, $\mathrm{CuK} \alpha$ radiation). Samples of the $2 \mathrm{LiBH}_{4}-\mathrm{Mg}_{2} \mathrm{FeH}_{6}$ composite were prepared by grinding synthesized $\mathrm{Mg}_{2} \mathrm{FeH}_{6}$ powder with commercial $\mathrm{LiBH}_{4}$ (Sigma-Aldrich) in a glove box filled with recirculated argon atmosphere. All subsequent handling of such samples took place in the glove box.

All thermodynamic and kinetic measurements of the hydrogenation/dehydrogenation reactions were done by the Sievert-type equipment. The PCI (Pressure-Composition-Isotherm) experiments on hydrogenation were carried out with the same conditions reported previously. ${ }^{8}$ In kinetic isothermal-isobaric experiments of dehydrogenation, a $0.2 \mathrm{~g}$ amount of the composite was loaded into the $5 \mathrm{~cm}^{3}$ sample holder, and after evacuation hydrogen gas of high purity $(99.9995 \%)$ was introduced at room temperature (RT) and high pressure (100 bar). The sample was heated to the set temperature, then pressure was decreased isothermally to the set value, and the kinetic measurement began. The amount of evolved $\mathrm{H}_{2}$ gas vs. time was determined by recording pressure increments at short intervals of $1 \mathrm{~min}$; these were immediately compensated by the system so as to keep $p\left(\mathrm{H}_{2}\right)$ constant at the set value throughout the whole reaction. At the end, $p$ was anyway slightly higher than its initial value by about 2-3\%, with larger relative increase at lower pressures. In the case of hydrogenation reactions, the sample was brought to the required temperature just after evacuation, and then $p\left(\mathrm{H}_{2}\right)$ was increased to the wanted value isothermally, before starting the kinetic measurements. Each sample underwent the following cycles of measurements: at first, the irreversible A dehydrogenation; then three-four cycles of $\mathrm{C}$ dehydrogenation $-\mathrm{C}$ rehydrogenations steps. Tests on the reproducibility of kinetic results with respect to cycling were quite satisfactory. 


\section{RESULTS AND DISCUSSION}

3.1. Van't Hoff plot for hydrogenation of $\mathbf{2 L i H}+\mathbf{M g B}$. In Figure 1, the van't Hoff plots $\ln \left(p_{e}\right.$ bar $)=\Delta_{r} S / R-\Delta_{r} H / R T$ of the $\mathrm{A}, \mathrm{B}$ and $\mathrm{C}$ dehydrogenation reactions obtained from PCI measurements in the previous work ${ }^{8}$ are shown as full lines. In the same paper some preliminary data on $\mathrm{C}$ re-hydrogenation were reported, showing that that reaction is reversible at variance with the irreversibility of reaction A. In the present work more PCI results were obtained, so as to build up van't Hoff plots also for $\mathrm{C}$ and $\mathrm{B}$ hydrogenation reactions, which are shown in Figure 1 as dashed lines.

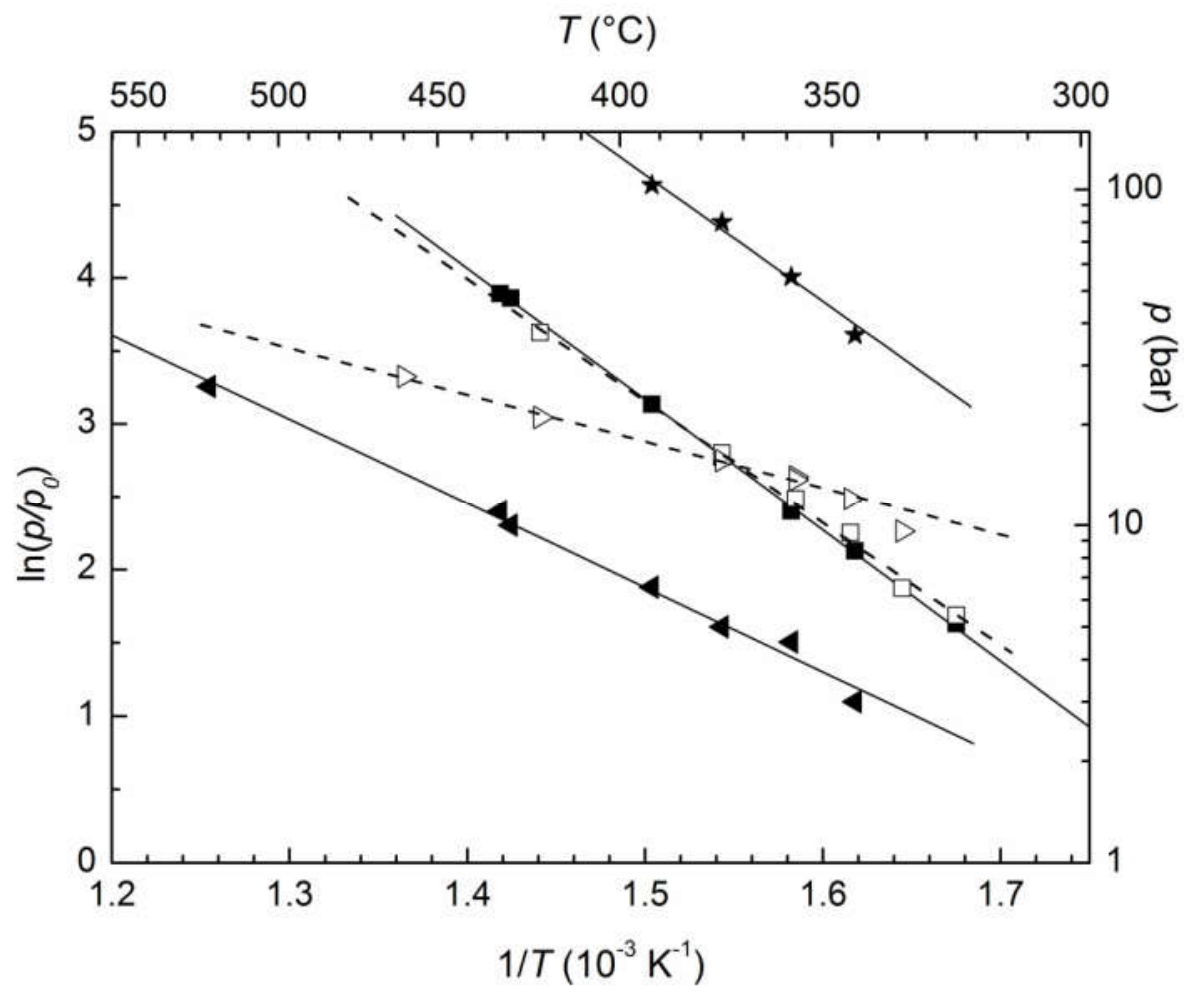

Figure 1. Van't Hoff plots of the A (stars), B (squares), and C (triangles) dehydrogenation reactions, ${ }^{8}$ and of the B (open squares) and C (open triangles) hydrogenation processes (this work).

The B line is nearly coincident with the corresponding one for dehydrogenation, confirming the well known good reversibility of B reaction. On the other hand, a strong hysteresis increasing 
with decreasing temperature is observed in the $\mathrm{C}$ case. Further, a peculiar feature appears immediately: the $\mathrm{C}$ hydrogenation line crosses the $\mathrm{B}$ one at about $370{ }^{\circ} \mathrm{C}$, so that above that temperature the reaction occurs as $2 \mathrm{LiH}+\mathrm{MgB}_{2}+3 \mathrm{H}_{2} \rightarrow 2 \mathrm{LiBH}_{4}+\mathrm{Mg}$, whereas below $370{ }^{\circ} \mathrm{C}$ the slightly different path $2 \mathrm{LiH}+\mathrm{MgB}_{2}+4 \mathrm{H}_{2} \rightarrow 2 \mathrm{LiBH}_{4}+\mathrm{MgH}_{2}$ is observed. In the latter case, the B process $\mathrm{Mg}+\mathrm{H}_{2} \rightarrow \mathrm{MgH}_{2}$ occurring at lower pressure consumes the Mg excess coming from $\mathrm{Mg}_{2} \mathrm{FeH}_{6}$ decomposition. The two variants of $\mathrm{C}$ hydrogenation reaction share approximately the same van't Hoff plot with $\Delta_{r} H=-27(2) \mathrm{kJ} \operatorname{mol}\left(\mathrm{H}_{2}\right)^{-1}$ and $\Delta_{r} S=-64(2) \mathrm{J} \mathrm{K}^{-1} \operatorname{mol}\left(\mathrm{H}_{2}\right)^{-1}$; cf. the values for $\mathrm{C}$ dehydrogenation ${ }^{8} \Delta_{r} H=48(2) \mathrm{kJ} \operatorname{mol}\left(\mathrm{H}_{2}\right)^{-1}$ and $\Delta_{r} S=87(2) \mathrm{J} \mathrm{K}^{-1} \operatorname{mol}\left(\mathrm{H}_{2}\right)^{-1}$. The much smaller slope of the hydrogenation line makes the hysteresis gap to widen significantly at lower temperatures, consistently with what expected as reversibility is favoured by higher $T$ values.

3.2. Isothermal kinetic curves. Kinetic measurements in isothermal-isobaric mode were performed on the $\mathrm{A}$ and $\mathrm{C}$ dehydrogenation reactions at several $T$ and $p$ values, which were selected taking into account the corresponding thermodynamic van't Hoff plots. Some preliminary results were obtained also for $\mathrm{C}$ hydrogenation. For a given reaction, the equilibrium $\mathrm{H}_{2}$ pressure $p_{e}(T)$ is calculated on the basis of the reaction enthalpies and entropies reported in Table 1 of Ref. 8 (and given above in the $\mathrm{C}$ hydrogenation case). For each temperature, measurements were repeated at different values of overpressure $\Delta p / p=\left(p-p_{e}\right) / p_{e}$. Although this is usually negative for dehydrogenation and positive for hydrogenation, non zero reaction rates were observed also for small $\Delta p / p$ values with the 'wrong' sign, as will be discussed below. Results of kinetic measurements are reported as curves of the normalized degree of reaction advancement $\xi$ (vs. a total of 3.2 and $2.0 \mathrm{wt} \%\left(\mathrm{H}_{2}\right)$ for the $\mathrm{A}$ and $\mathrm{C}$ cases, respectively) against time $t$. As examples, the curves obtained for dehydrogenation $\mathrm{A}$ at $358^{\circ} \mathrm{C}$ and $\Delta p / p=-0.233,-0.067,0.088$ are shown in Figure 2, and those for $\mathrm{C}$ at $375^{\circ} \mathrm{C}$ and $\Delta p / p=-0.255,-0.149,-0.021,0.064$ are shown in Figure 3. 


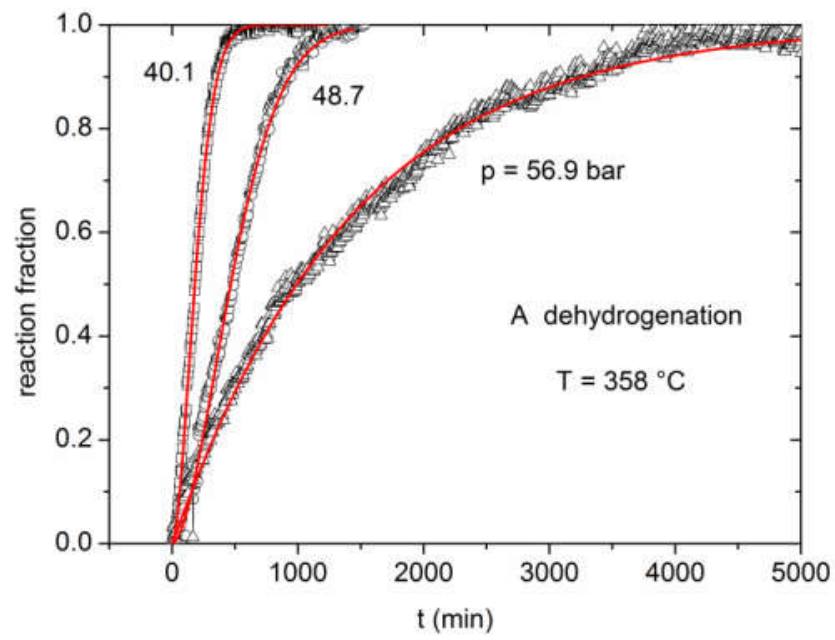

Figure 2. Isothermal kinetic plots for the A reaction $\left(2 \mathrm{Mg}_{2} \mathrm{FeH}_{6}+2 \mathrm{LiBH}_{4} \rightarrow 2 \mathrm{LiH}+4 \mathrm{MgH}_{2}+\right.$ $\left.2 \mathrm{FeB}+5 \mathrm{H}_{2}\right)$ at three different hydrogen pressures. Avrami-like fitting curves are shown.

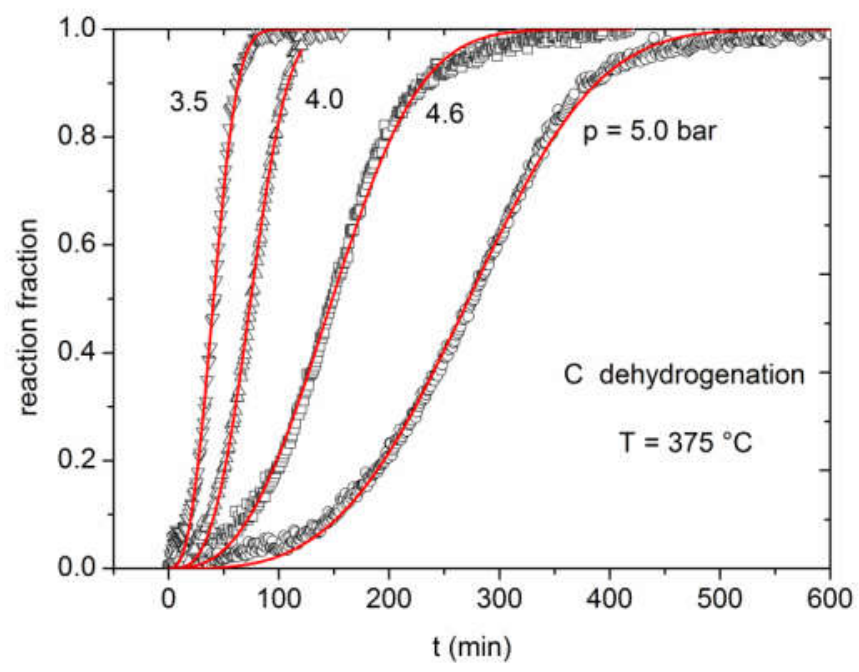

Figure 3. Isothermal kinetic plots for the $\mathrm{C}$ dehydrogenation $\left(2 \mathrm{LiBH}_{4}+\mathrm{Mg} \rightarrow 2 \mathrm{LiH}+\mathrm{MgB}_{2}+\right.$ $\left.3 \mathrm{H}_{2}\right)$ at four different hydrogen pressures. Avrami-like fitting curves are shown.

All kinetic curves for the $\mathrm{C}$ reaction have a clear sigmoidal shape, so as to immediately suggest use of the Avrami (or Johnson-Mehl-Avrami-Kolmogorov (JMAK)) equation ${ }^{22-27} \xi(t)=1-\exp [-$ $\left.(k t)^{n}\right]$ for fitting data and derive the rate constant $k$. In the A case, where the reaction kinetics is clearly much slower (compare Figures 2 and 3), the shape of curves rather resembles that of firstorder kinetics. However, the JMAK formula is able to include also that as a particular case, so that 
the fitting was performed by the same equation for all $\mathrm{A}$ and $\mathrm{C}$ data. In each case the calculation was carried out both on relaxing the $n$ exponent, and on fixing it at the closest integer value. The fitted rate constant $k$ did not change significantly, proving to be rather independent of minor exponent variations. For the A reaction, the relaxed $n$ exponent ranged between 1 and 2, whereas in the $\mathrm{C}$ case values between 2.5 and 3.5 were obtained. The quality of the fitting was always very good, with an average $R^{2}$ index value of $99.5 \%$ (cf. Figures 2 and 3). However, we also tried different kinetic models, like the 'contracting volume' or 'moving boundary' equation, ${ }^{27} \xi(t)=1-(1-$ $k t)^{3}$, and the diffusion-controlled one, ${ }^{27} \xi(t)=1-\left[1-(k t)^{1 / 2}\right]^{3}$. In all cases the fit was definitely much worse than with the JMAK formula. Taking into account the physical basis underlying the Avrami model, and the fitted $n$ exponent values, we can conclude that the $\mathrm{C}$ reaction kinetics is controlled by the slow step of growth of nuclei with $n$ dimensions in cases with the lower $n$ exponents, with a contribution of the nucleation step when $n>3$. For the slower A reaction, a pure growth mechanism with low grain dimensionality seems to be appropriate.

A preliminary kinetic study was also carried out on the $\mathrm{C}$ hydrogenation reaction, by performing a limited number of measurements. In Figure 4 examples of isotherms for a single temperature and different overpressure values $(0.105,0.133,0.319)$ are shown. Such curves resemble more those of dehydrogenation $\mathrm{A}$ than $\mathrm{C}$, as they lack the sigmoidal shape of the latter. The Avrami equation proved yet to be quite adequate to fit data, with a $n$ exponent slightly smaller than 1.

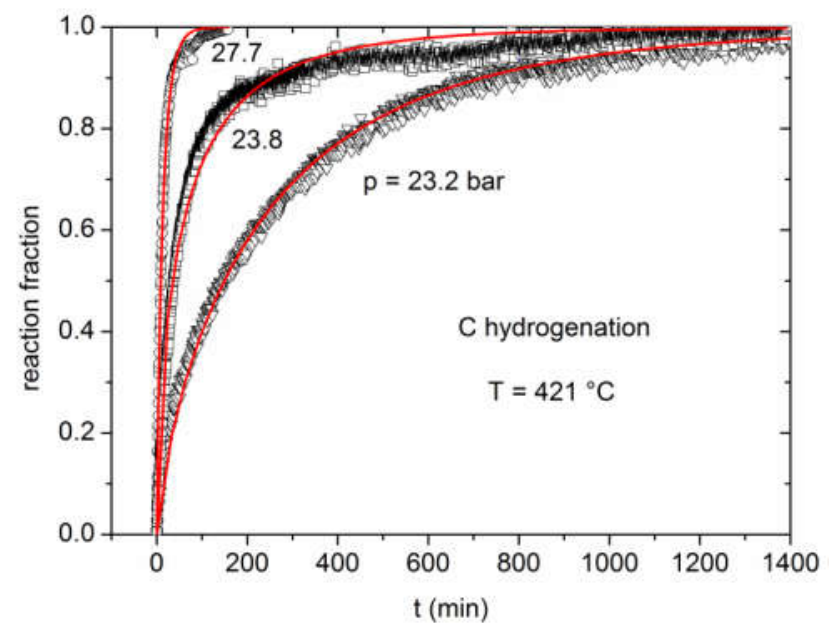


Figure 4. Isothermal kinetic plots for the $\mathrm{C}$ hydrogenation $\left(2 \mathrm{LiH}+\mathrm{MgB}_{2}+3 \mathrm{H}_{2} \rightarrow 2 \mathrm{LiBH}_{4}+\mathrm{Mg}\right)$ at three different hydrogen pressures. Avrami-like fitting curves are shown.

3.3. Rate constant dependence on temperature and overpressure. By the JMAK fitting of kinetic curves, a set of rate constants $k$ associated to different temperatures and overpressures was derived for each of the $\mathrm{A}$ and $\mathrm{C}$ dehydrogenation reactions, obtaining corresponding numerical tables of $k(T, \Delta p / p)$ data. Similarly to what proposed in previous work, ${ }^{13}$ we assume that this functional dependence can be factorized into the product

$$
k=k_{0}(T) k_{1}(\Delta p / p)
$$

where $k_{0}$ is defined as the rate constant at vanishing overpressure (i.e. for $p=p_{e}$ ), so that the condition $k_{1}(\Delta p / p=0)=1$ must be fulfilled. More generally, the second factor $k_{1}$ should be written as $k_{1}(T, \Delta p / p)$, in order to include a possible coupling of its thermal and pressure dependences.

At constant $T$, we tried to fit the $k(\Delta p / p)$ empirical function at first by the power law $\ln k=$ $a \ln (\Delta p / p+1)+b$, obtaining satisfactory results but with quite large values of the $-a$ exponent (between 5 and 6). This would indicate a stronger kinetic effect of overpressure than in the study of sodium alanate, ${ }^{13,14}$ where a linear or parabolic dependence of the rate constant on overpressure was observed. Then an exponential law was tested, according to

$$
\ln k=a(\Delta p / p)+b
$$

this linear relationship between $\ln k$ and overpressure proved to be always well obeyed, and thus the exponential empirical law was adopted for treatment of all data. Indeed this formula is easily integrated into a kinetic theoretical frame, as will be discussed below, at variance with the power 
law with large variable exponent. An example of two experimental straight lines of $\ln k$ vs. $\Delta p / p$ for the $\mathrm{C}$ dehydrogenation is shown in Figure 5. The fitted $a$ and $b$ linear coefficients for all measured data of the $\mathrm{A}$ and $\mathrm{C}$ reactions are reported in Table 1.

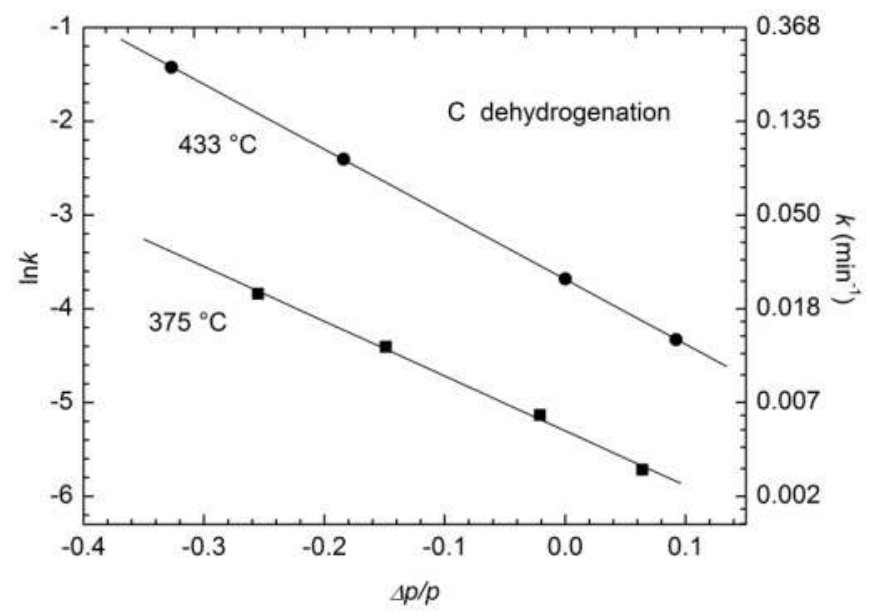

Figure 5. Logarithm of the rate constant $k\left(\mathrm{~min}^{-1}\right)$ for the $\mathrm{C}$ dehydrogenation plotted against overpressure $\Delta p / p=\left(p-p_{e}\right) / p_{e}$ at two different temperatures.

Table 1. Coefficients of the $\ln k=a(\Delta p / p)+b$ empirical relation between reaction rate constant $k$ $\left(\min ^{-1}\right)$ and overpressure $\Delta p / p$, fitted to isothermal kinetic measurement data.

\begin{tabular}{lll}
\hline $\mathrm{T}\left({ }^{\circ} \mathrm{C}\right)$ & $a$ & $b$
\end{tabular}

A dehydrogenation

$-3.3-7.78$

343

$-4.2$

$-6.92$

358

$-5.8 \quad-6.75$

363

$-5.3-6.25$

376

$-5.4 \quad-5.80$

C dehydrogenation 
C hydrogenation

The zero-order coefficient in (2) can be written as $b=\ln k_{0}$, according to Eqn. (1) and the definition of $k_{0}$. Eqn. (2) can then be restated as:

$$
k=k_{0}(T) \exp [a(\Delta p / p)],
$$

so that $k_{l}=\exp [a(\Delta p / p)]$ is obtained with the $a$ coefficient including a possible thermal dependence. The Arrhenius-like dependence on temperature can be reasonably assumed for $k_{0}(T)$ :

$$
k_{0}=f \exp \left(-\Delta G_{a}^{0} / R T\right)=f \exp \left(\Delta S_{a}^{0} / R\right) \exp \left(-E_{a}^{0} / R T\right)=A_{0} \exp \left(-E_{a}^{0} / R T\right),
$$

where $f$ is an effective vibrational frequency (or a dimensional coefficient time $e^{-1}$ ), $\Delta G_{a}^{0}$ and $\Delta S_{a}^{0}$ are the activation Gibbs free energy and entropy, respectively, at vanishing overpressure, and $E_{a}^{0}$ is the corresponding activation energy (approximately equal to the activation enthalpy $\Delta H_{a}^{0}$ at the 
pressures of interest). On looking at values in Table 1, a decreasing trend of $a$ with increasing temperature appears clearly for both reactions; this can be simply modelled according to $a=a_{0}+$ $a_{1} / T$, with $a_{0}<0$ and $a_{1}>0$. This means that the higher the temperature, the more effective is overpressure to increase the reaction rate. On substitution into the $k$ expression, one obtains:

$k=k_{0} \exp \left[\left(a_{0}+a_{1} / T\right)(\Delta p / p)\right]=f \exp \left[\Delta S_{a}^{0} / R+a_{0}(\Delta p / p)\right] \exp \left[-\left(E_{a}^{0}-R a_{1}(\Delta p / p)\right) / R T\right]=$
$A \exp \left(-E_{a} / R T\right)$.

Eqn (5) can be interpreted by stating that (negative) overpressure has a twofold effect: it increases both the activation entropy and the activation energy. The second effect is due to the thermal dependence of the $a$ coefficient with positive $a_{l}$ parameter, and it reduces the increase of reaction rate $k$ due to the first one:

$$
\Delta S_{a}=\Delta S_{a}^{0}+R a_{0}(\Delta p / p) ; \quad E_{a}=E_{a}^{0}-R a_{1}(\Delta p / p)
$$

The thermal dependence of the rate constant was analyzed by plotting $b=\ln k_{0}$ against $1 / T$ from data of Table 1 for each of the $\mathrm{A}$ and $\mathrm{C}$ dehydrogenation reactions. According to the Arrhenius relation (4): $\ln k_{0}=-E_{a} / R T+\ln A_{0}$, so that by a linear fit of $\ln k_{0}$ vs. $1 / T$ the activation energy and the pre-exponential factor $A_{0}$ at $\Delta p / p=0$ can be obtained. The procedure was then repeated for nonvanishing overpressure values, by plotting $\ln k$ calculated by eqn. (2), instead of $\ln k_{0}$, vs. $1 / T$. In this way the Arrhenius parameters were obtained as functions of $\Delta p / p$, according to the dependence appearing in eqn. (5). The results are reported in Table 2 for each reaction and for different overpressure values. 
Table 2. Arrhenius parameters (activation energy and logarithm of the pre-exponential factor) from kinetic measurements on dehydrogenation reactions $\mathrm{A}$ and $\mathrm{C}$ at different overpressures $\Delta p / p$. The e.s.d.'s are given in parentheses.

\begin{tabular}{lll}
\hline$\Delta p / p$ & $E_{a}\left(\mathrm{~kJ} \mathrm{~mol}^{-1}\right)$ & $\ln \left(A / \mathrm{min}^{-1}\right)$ \\
\hline A dehydrogenation & & \\
0 & $118(13)$ & $16(2)$ \\
-0.10 & $132(10)$ & $19(2)$ \\
-0.20 & $148(7)$ & $23(1)$ \\
-0.30 & $163(6)$ & $26(1)$ \\
C dehydrogenation & & \\
0 & $110(7)$ & $15(1)$ \\
-0.10 & $130(10)$ & $19(2)$ \\
-0.20 & $139(13)$ & $22(2)$ \\
-0.30 & $149(17)$ & $24(3)$ \\
\hline
\end{tabular}

In Figures 6 and 7 the Arrhenius plots are shown in the $\mathrm{A}$ and $\mathrm{C}$ cases, respectively, for $\Delta p / p=0$ and -0.30. The corresponding linear relationships (6) are as follows:

$E_{a}=-151(\Delta p / p)+118 \mathrm{~kJ} \mathrm{~mol}^{-1}, \ln \left(A / \mathrm{min}^{-1}\right)=-34(\Delta p / p)+16$, for reaction $\mathrm{A} ;$

$E_{a}=-160(\Delta p / p)+110 \mathrm{~kJ} \mathrm{~mol}^{-1}, \quad \ln \left(A / \mathrm{min}^{-1}\right)=-34(\Delta p / p)+15, \quad$ for reaction $\mathrm{C}$. 


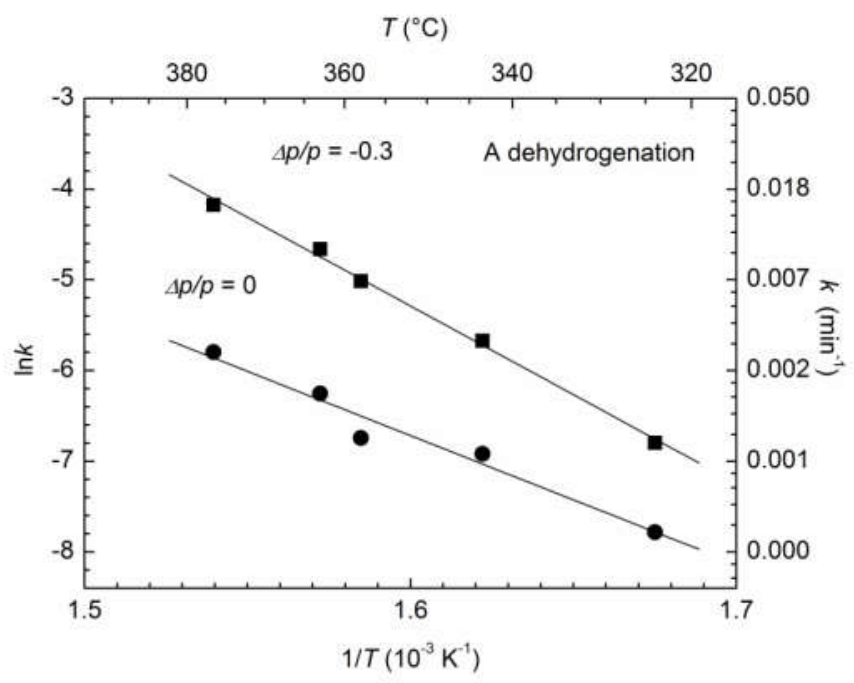

Figure 6. Arrhenius plots for the A dehydrogenation reaction at two different values of the overpressure $\Delta p / p$.

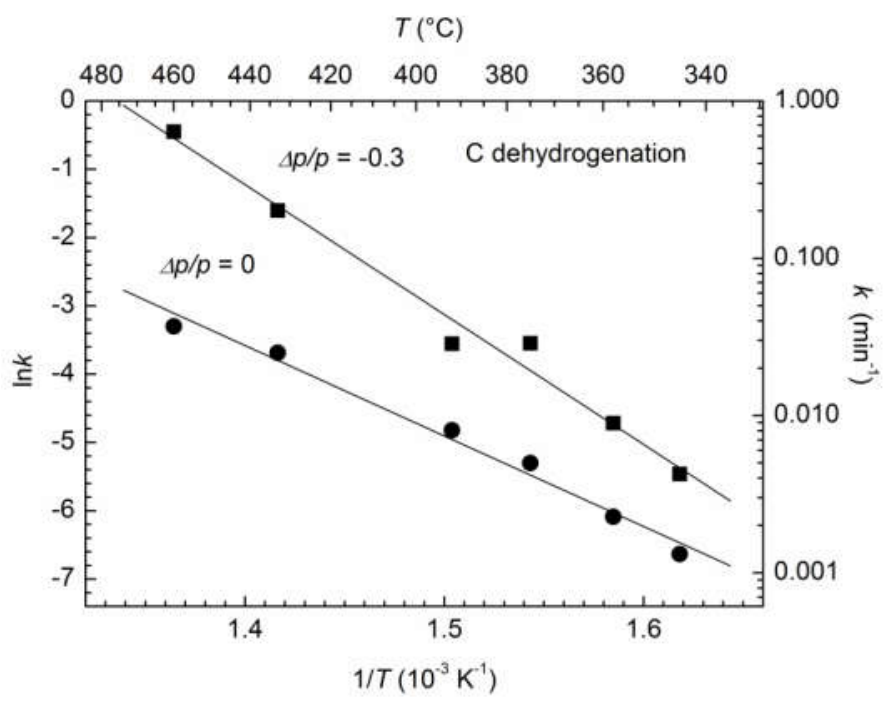

Figure 7. Arrhenius plots for the $\mathrm{C}$ dehydrogenation reaction at two different values of the overpressure $\Delta p / p$.

The coefficients of the $a=a_{0}+a_{1} / T$ expression turn out to be for A: $a_{0}=-34, a_{1}=18 \times 10^{3} \mathrm{~K}$; for C: $a_{0}=-34, a_{l}=19 \times 10^{3} \mathrm{~K}$. Such coefficients could have been obtained also by direct fitting of the $a$ values reported in Table 1 against $1 / T$, where the scatter of data shows that they are affected by a significant uncertainty. However, the overall trend is well defined, with not only the activation energies and entropies at $\Delta p / p=0$, but also their overpressure coefficients very similar for both dehydrogenation reactions. This suggests that the temperature/overpressure effects on the rate 
constant are controlled by physical features of the solid phases present (surface state and extension, defect distribution, interface energy, etc.), which are similar in the A and C cases, rather than by their chemical specificities.

For results of $\mathrm{C}$ hydrogenation, the rate constant $k$ vs. $\Delta p / p$ was again fitted by eqn. (2). The $a$ and $b$ coefficients obtained are reported in Table 1 for only two $T$ values, so that the Arrhenius-like analysis of results could not be done because of insufficient data. However, one can notice that the $|a|$ values are over $50 \%$ bigger than the corresponding ones for dehydrogenation, indicating a significantly larger effect of overpressure in accelerating hydrogenation $(\Delta p / p>0)$ with respect to dehydrogenation $(\Delta p / p<0)$ for the $\mathrm{C}$ reaction. Of course, the sign of $a$ changes with reversion of the reaction direction.

3.4. Thermodynamic driving force and irreversibility. More insight into the fundamental kinetic meaning of the previous analysis can be obtained by relating overpressure $\Delta p / p$ to the thermodynamic driving force $\Delta G$. According to basic thermodynamics, $\Delta G= \pm R T \ln (\Delta p / p+1)$, with positive and negative signs for dehydrogenation and hydrogenation directions, respectively; for $|\Delta p / p|$ smaller enough than $1, \Delta G \approx \pm R T(\Delta p / p)$, so that by substitution of $\Delta p / p$ in eqns. (3) and (4) we obtain:

$$
k=k_{0} \exp ( \pm a \Delta G / R T)=f \exp \left[-\left(\Delta G_{a}^{0} \pm a \Delta G\right) / R T\right] .
$$

This relationship connects the action of the thermodynamic driving force to the Arrhenius formalism, based on the activated state concept. It resembles somehow the Tafel equation of electrochemical kinetics, ${ }^{28}$ where the driving force $\Delta G$ is proportional to overvoltage rather than to overpressure. However, there is a fundamental difference, because in Tafel equation $a$ is replaced by the transfer coefficient $1 \geq \alpha \geq 0$; here, on the other hand, $a$ is an empirical parameter with absolute value larger than 1 . This means that, in the present instance, the overpressure driving force 
has a stronger action in increasing the rate constant: in addition to the maximum 'transfer' effect $(\alpha=1)$, there is a further direct reduction of the activation barrier $\Delta G_{a}^{0}$ by a $(|a|-1)|\Delta G|$ amount.

In cases where the dehydrogenation reaction is irreversible (A), or where it is reversible but with a large hysteresis (C), the Tafel (or Butler-Volmer) approach ${ }^{28}$ of electrochemical kinetics should be modified. In fact, it is not possible any more to use the same kinetic diagram of $G$ free energy along the reaction coordinate in both directions of the transformation. One is forced either to consider only one of the two directions (A dehydrogenation), or to consider two different $G$ diagrams specific for each direction ( $\mathrm{C}$ dehydrogenation and hydrogenation). In particular, in the latter case two 'equilibrium' pressures are defined at each temperature: $p_{e l}(T)$ for dehydrogenation and $p_{e 2}(T)$ for hydrogenation, with $p_{e l}(T)<p_{e 2}(T)$ : see the two experimental van't Hoff lines in Figure 1. In this instance 'equilibrium' means simply that both phase assemblages (cf. $2 \mathrm{LiH}+\mathrm{MgB}_{2}+3 \mathrm{H}_{2}$ and $2 \mathrm{LiBH}_{4}+\mathrm{Mg}$ ) may coexist together at either $p_{e 1}(T)$ or $p_{e 2}(T)$, but the direction of transformation is unique and different in each case. Therefore, using $p_{e 1}$ and $p_{e 2}$ as reference pressures for defining overpressures (as we did to analyze kinetic data in Table 1) may not be the only possible choice, particularly in the region $p_{e 1}<p<p_{e 2}(T)$, where overpressure ranges with 'wrong' signs (positive for dehydrogenation, negative for hydrogenation) are observed. An empirical alternative to remove this feature could be to use the average $\left(p_{e 1}+p_{e 2}\right) / 2$ as single reference pressure for both reactions. Further investigations on that are planned in our future work.

\section{CONCLUSIONS}

The kinetic properties of $\mathrm{H}_{2}$ desorption-sorption reactions of the $2 \mathrm{LiBH}_{4}-\mathrm{Mg}_{2} \mathrm{FeH}_{6}$ assemblage were determined by isothermal-isobaric experiments, with a particular focus on the role of overpressure and its coupling with temperature. By extending measurements to conditions close to equilibrium, where reactions are very slow, a convenient range of overpressures could be 
covered. This allowed us to explore the kinetic effect of $\Delta p / p$ in a proper way, and to interpreted the data on the basis of an exponential dependence of the reaction rate constants on overpressure. Such a result fits naturally with the conventional Arrhenius formalism, suggesting simple linear relations of activation energy and entropy with overpressure. As $\Delta p / p$ is straightforwardly connected to the thermodynamic driving force $\Delta G$, the empirical results found can be accounted for by a consistent theoretical frame related to that used in electrochemical kinetics. This analysis can have a broader interest for application to kinetic properties of a large class of solid-gas reactions, provided that their rates are compatible with measurable overpressure effects. However, irreversibility and/or hysteresis conditions specific of these processes require to extend and generalize the approach here proposed, and further research is planned in that direction.

\section{AUTHOR INFORMATION}

Corresponding Author

*E-mail: catti@mater.unimib.it; tel. +390264485139 


\section{REFERENCES}

(1) Vajo, J.J.; Olson, G.L. Hydrogen Storage in Destabilized Chemical Systems. Scripta Mater. 2007, 56, 829-834.

(2) David, W.I.F. Effective Hydrogen Storage: a Strategic Chemistry Challenge. Faraday Discuss. 2011, 151, 399-414.

(3) Vajo, J.J.; Skeith, S.L.; Mertens, F. Reversible Storage of Hydrogen in Destabilized LiBH4. J. Phys. Chem. B 2005, 109, 3719-3722.

(4) Bösenberg U.; Doppiu S.; Mosegaard L.; Berkhordarian G.; Eigen N.; Borgschulte A.; Jensen T.R.; Cerenius Y.; Gutfleisch O.; Klassen T. et al. Hydrogen Sorption Properties of $\mathrm{MgH}_{2}-\mathrm{LiBH}_{4}$ Composites. Acta Mater. 2007, 55, 3951-3958.

(5) Pinkerton, F.E.; Meyer, M.S.; Meisner, G.P.; Balogh, M.P.; Vajo, J.J. Phase Boundaries and Reversibility of $\mathrm{LiBH}_{4} / \mathrm{MgH}_{2}$ Hydrogen Storage Material. J. Phys. Chem. C 2007, 111, 1288112885.

(6) Zhang, Y.; Tian, Q.; Chu, H.; Zhang, J.; Sun, L.; Sun, J.; Wen, Z. Hydrogen De/Resorption Properties of the $\mathrm{LiBH}_{4}-\mathrm{MgH}_{2}-\mathrm{Al}$ System. J. Phys. Chem. C 2009, 113, 21964-21969.

(7) Siegel, D.J.; Wolverton, C.; Ozolins, V. Thermodynamic Guidelines for the Prediction of Hydrogen Storage Reactions and their Application to Destabilized Hydride Mixtures. Phys. Rev. B 2007, 76, 134102/1-5.

(8) Ghaani, M.R.; Catti, M.; Nale, A. Thermodynamics of Dehydrogenation of the 2LiBH4$\mathrm{Mg}_{2} \mathrm{FeH}_{6}$ Composite. J. Phys. Chem. C 2012, 116, 26694-26699.

(9) Züttel A.; Rentsch, S.; Fischer, P.; Wenger, P.; Sudan, P.; Mauron, Ph.; Emmenegger, Ch. Hydrogen Storage Properties of $\mathrm{LiBH}_{4}$. J. Alloys Compd. 2003, 356-357, 515-520. 
(10) Bogdanovic, B.; Reiser, A.; Schlichte, K.; Spliethoff, B.; Tesche, B. Thermodynamics and Dynamics of the Mg-Fe-H System and its Potential for Thermochemical Thermal Energy Storage. J. Alloys Compd. 2002, 345, 77-89.

(11) Langmi, H.W.; McGrady, G.S.; Newhouse, R.; Rönnebro, E. $\mathrm{Mg}_{2} \mathrm{FeH}_{6}-\mathrm{LiBH}_{4}$ and $\mathrm{Mg}_{2} \mathrm{FeH}_{6-}$ $\mathrm{LiNH}_{2}$ Composite Materials for Hydrogen Storage. Int. J. Hydrogen Energy 2012, 37, 6694-6699. (12) Deng, S.; Xiao, X.; Han, L.; Li, Y.; Li, S.; Ge, H.; Wang, Q.; Chen, L Hydrogen Storage Performance of $5 \mathrm{LiBH}_{4}+\mathrm{Mg}_{2} \mathrm{FeH}_{6}$ Composite System. Int. J. Hydrogen Energy 2012, 37, 67336740.

(13) Lozano, G.A.; Na Ranong, C.; Bellosta von Colbe, JM.; Bormann, R.; Fieg, G.; Hapke, J.; Dornheim, M. Empirical Kinetic Model of Sodium Alanate Reacting System (I). Hydrogen Absorption. Int. J. Hydrogen Energy 2010, 35, 6763-6772.

(14) Lozano, G.A.; Na Ranong, C.; Bellosta von Colbe, JM.; Bormann, R.; Fieg, G.; Hapke, J.; Dornheim, M. Empirical Kinetic Model of Sodium Alanate Reacting System (II). Hydrogen Desorption. Int. J. Hydrogen Energy 2010, 35, 7539-7546.

(15) Sabitu, S.T.; Fagbami, O; Goudy, A.J. Kinetics and Modeling Study of Magnesium Hydride with Various Additives at Constant Pressure Thermodynamic Driving Forces. J. Alloys Compd. 2011, 509S, S588-S591.

(16) Evard, E.; Gabis, I.; Yartys, V.A. Kinetics of Hydrogen Evolution from $\mathrm{MgH}_{2}$ : Experimental Studies, Mechanism and Modelling. Int. J. Hydrogen Energy 2010, 35, 9060-9069.

(17) Blaine, R.L.; Kissinger, H.E. Homer Kissinger and the Kissinger Equation. Thermochim. Acta 2012, 540, 1-6.

(18) Bradley, R.S. The Energetics and Statistical Mechanics of the Kinetics of Solid-Solid Reactions. J. Phys. Chem. 1956, 60, 1347-1354.

(19) Pokol, G. The Thermodynamic Driving Force in the Kinetic Evaluation of Thermoanalytical Curves. J. Thermal Anal. Calorim. 2000, 60, 879-886. 
(20) Zhang, X.; Yiang, R.; Qu, J.; Zhao, W.; Xie, L.; Tian, W.; Li, X. The Synthesis and Hydrogen Storage Properties of Pure Nanostructured $\mathrm{Mg}_{2} \mathrm{FeH}_{6}$. Nanotechnology 2010, 21, 095706/1-7.

(21) Polanski, M.; Plocinski, T.; Kunce, I.; Bystrzycki, J. Dynamic Synthesis of Ternary $\mathrm{Mg}_{2} \mathrm{FeH}_{6}$. Int. J. Hydrogen Energy 2010, 35, 1257-1266.

(22) Avrami, M. Kinetics of Phase Change. I. General Theory. Journal of Chemical Physics 1939, 7,1103-1112.

(23) Avrami, M. Kinetics of Phase Change. II. Transformation-Time Relations for Random Distribution of Nuclei. Journal of Chemical Physics 1940, 8, 212-224.

(24) Avrami, M. Granulation, phase change and microstructure. Kinetics of phase change. III. Journal of Chemical Physics 1941, 9, 177-184.

(25) Jena, A.K.; Chaturvedi, M.C. Phase Transformations in Materials; Prentice Hall: New Jersey, 1992.

(26) Cahn, J.W. Transformation Kinetics during Continuous Cooling. Acta Metallurg. 1956, 4, $\underline{572-575 .}$

(27) Galway, A.K.; Brown, M.E. Kinetic Background to Thermal Analysis and Calorimetry in Handbook of Thermal Analysis and Calorimetry, Vol. 1, ed. Brown, M. E., series ed. Gallager, P. K..; Elsevier Science B.V.: Amsterdam, 1998.

(28) Bard, A.; Faulkner, L. Electrochemical Methods. Fundamentals and Applications; John Wiley and Sons: New York, 2001. 
Table of Contents Image

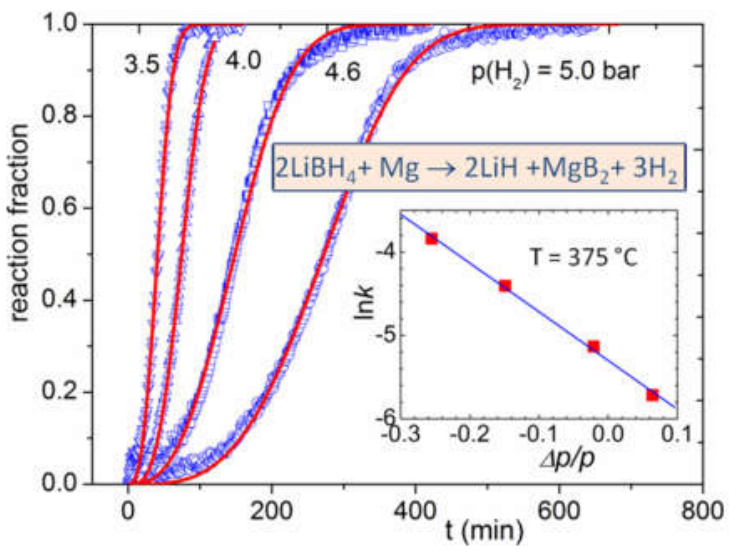

